\title{
The Factors Affecting Smoking Cessation and Efficacy of Quitting Methods
}

\author{
Esen Sayın Gülensoy ${ }^{1}$, Evrim Eylem Akpınar ${ }^{1}$ \\ ${ }^{1}$ Ufuk University, Faculty of Medicine, Department of Chest Diseases, Ankara, Turkey
}

Received:24 October 2019, Accepted 20 November 2019, Published online: 31 December 2019

(C) Ordu University Institute of Health Sciences, Turkey, 2019

\begin{abstract}
Objective: We aimed to compare the demographic-sociocultural characteristics of quitting and non-quitting individuals and to evaluate the factors affecting smoking cessation and success rates of treatment methods.

Methods: 179 patients were included in the study. Demographic characteristics, smoking behaviour, Fagerström nicotine dependence level were recorded. The treatment results at the end of the first year were evaluated. The efficacy of treatment methods used in the treatment of smoking dependence, gender, occupation, education, comorbidity, and family history were recorded in quitting and non-quitting individuals. Statistical analysis was performed using Statistical Package for Social Sciences Version 21.0 (SPSS-21.0).
\end{abstract}

Results: Of the 179 patients evaluated, 118 (65.6\%) were male and 71 (39.7\%) were married. The mean age was $41.5 \pm 13.7$ years. At the end of 12 months follow-up, 57 (31.8\%) had been quitted smoking. There was no difference between the quit and non-quit groups in terms of gender, age, working status and education level. It was found that being married and having no additional disease significantly increased smoking cessation rate $(p=0.049, p=0.010$, respectively). In both groups, combination of behavioural treatment and varenicline was the most common method. There was no significant difference among the pharmacological methods used.

Conclusion: In our study, smoking cessation rate was found to be $31.8 \%$. The efficacy of different treatment modalities was similar. Despite the current treatments, the rate of smoking cessation is not at the desired level and further studies are needed to develop new methods for smoking cessation treatment.

Key words: Tobacco use, smoking reduction, smoking cessation

Suggested Citation: Sayın Gulensoy E, Akpınar EE. The Factors Affecting Smoking Cessation and Efficacy of Quitting Methods. Middle Black Sea Journal of Health Science, 2019; 5(3): 168-174.

Address for correspondence/reprints:

Esen Sayın Gülensoy

Telephone number: +90(542) 6451911

E-mail: esen_sayin@hotmail.com

DOI: $10.19127 /$ mbsjohs. 637725

\section{Introduction}

One of the biggest social problems in the world and in our country is cigarette addiction (Karnath 2002). Cigarette addiction is defined by the World Health Organization (WHO) as a chronic disease with recurrences (WHO, Report on the Global Tobacco Epidemic, 2019). Active and passive smoking affects all organs, tissues and systems, leading to death, disease and disability (Mackay and Eriksen, 2002; Fried, 2003).

In Global Adult Tobacco Survey, 19.2 million people in Turkey (31.6\%) currently use tobacco products. The prevalence of tobacco use is still higher in men $(44.1 \%)$ than in women $(19.2 \%)$ (Global Adult Tobacco Survey, Turkey 2016). 
In the world, more than a billion smokers are addicts. Most of these addicts would like to quit, but $5 \%$ can receive comprehensive services for the treatment against tobacco addiction. Countries should establish effective and inexpensive intervention programs for those who smoke and willing to quit. The fight against smoking is the duty of all physicians and it is recommended to support the quitting efforts of individuals using tobacco (Mackay and Eriksen, 2002).

It is known that the programs implemented in specialized smoking outpatient clinics increase the success of smoking cessation (Parrott and Godfrey, 1998).

The aim of this study was to investigate the demographic-sociocultural characteristics of patients followed up at the smoking cessation clinic, factors affecting smoking cessation, and the success rates of smoking cessation methods.

\section{Methods}

The files of the patients who applied to the smoking cessation clinic of Ufuk University Dr. Ridvan Ege Hospital between the dates of January 2010 and December 2012 were retrospectively reviewed. The criteria for inclusion in the study were being $>18$ years of age and follow-up in our smoking cessation clinic for at least one year. Patients who were followed-up for less than one year, $\leq 18$ years of age and who had missing data on their file, and missing information about the smoking cessation treatment response were excluded from the study. All patients had Fagerström nicotine dependence test at their admission. Determination of addiction level is important for the choice of treatment and success of cessation. The Fagerström Test for Nicotine Dependence (FTND) is the most commonly used test for the assessment of cigarette dependence in daily practice (Demir, 2008). The Fagerström Tolerance Test was first proposed in 1978, and in 1991, Heatherton et al. (1991) called Fagerström Tolerance Scala. Adapting the test to Turkish was made by Uysal et al. (2004). Demographic characteristics, smoking behaviour and attitudes of the patients, FTND score, comorbid medical or psychiatric diseases and drugs used were recorded.

Behavioural therapies consisting of practical applications were recommended in our smoking cessation clinic. In order to cope with early withdrawal symptoms and late effects, the patient was advised to stay away from smoking environments, to be active, to use chewing gum, to perform deep breathing exercises and to prevent weight gain. Patients were given a telephone number to call if they needed it. They were evaluated psychologically during their regular follow-up. The treatment method (pharmacological and/or behavioural treatment), duration of treatment, gender, occupation, education, comorbidity, family history, smoking at home and addiction scores were recorded in subjects who quit and could not quit. The results of the treatment at the end of the first year were evaluated by using file data and contacting the patients by telephone.

Design of the study was summarized in figure 1 .

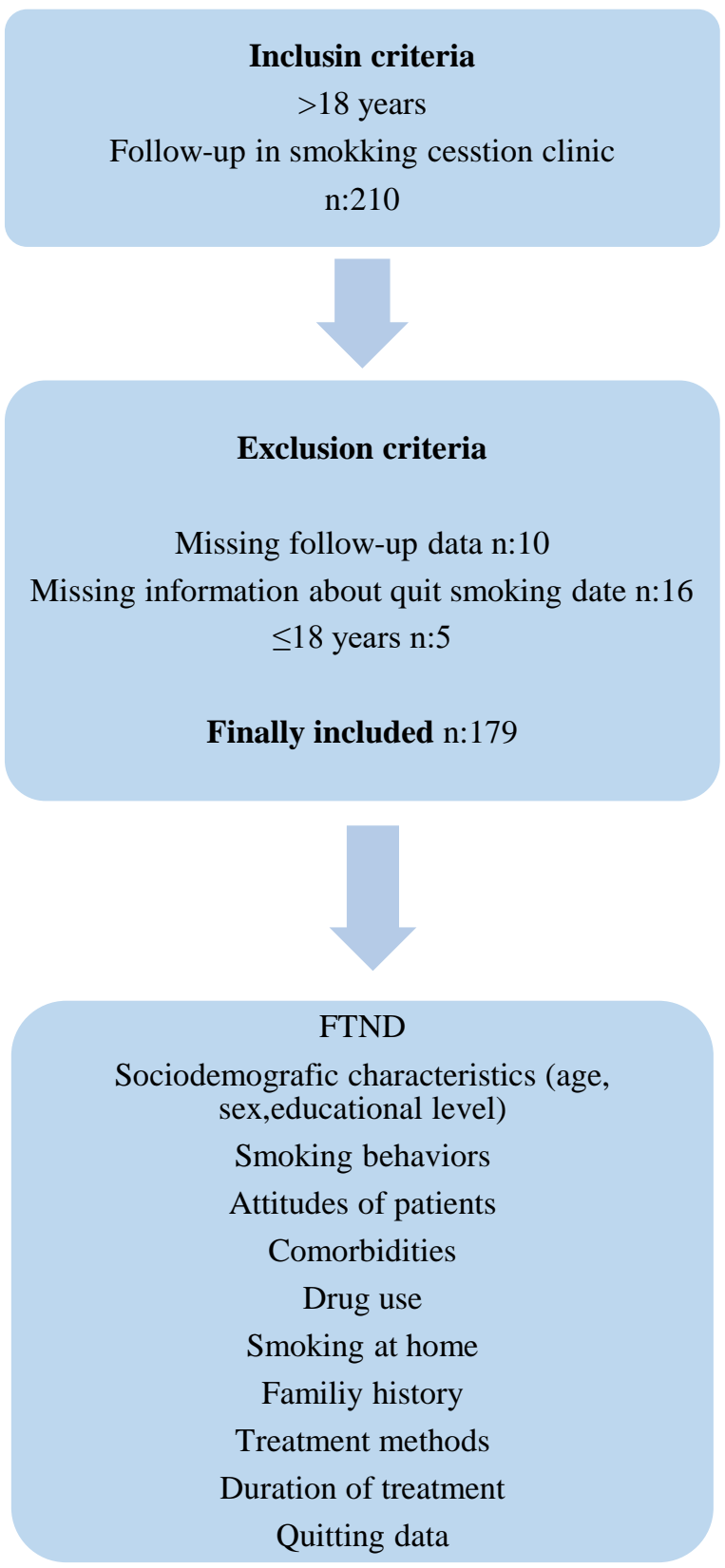

Figure 1. Design of the study 
Statistical analysis: Data were analysed using Statistical Package for Social Sciences Version 21.0 (SPSS-21.0). In the evaluation of the data, the Kolmogorov-Smirnov test was used to compare whether the variables were normally distributed or not. The $t$ test was used for normal distributions and Mann-Whitney U test was used for non-normally distributed variables. Chi-square analysis was used for categorical variables. Odds ratios were calculated by Cochran's and Mantel-Haenszel test. $\mathrm{p}<0.05$ was considered as statistically significant.

\section{Results}

Of the 210 individuals who applied to our outpatient clinic and completed the first year controls, 18-year-old patients $(n=5)$, who could not obtain information about the smoking cessation treatment response $(\mathrm{n}=16)$ and who had incomplete information on their file $(n=10)$ were excluded from the study. As a result, 179 patients were included to the study. The mean age was $41.5 \pm 13.7$ years and $118(65.6 \%)$ were male and $71(39.7 \%)$ were married. 141 people (78.8\%) were in high school and above. The highest rate of beginning to smoke was between the ages of 16 and 20 years (50.8\%).

Behavioural treatment was applied to all individuals who applied to the outpatient clinic. If moderate and high levels of addiction were detected, pharmacological treatment was recommended.

At the end of twelve-month follow-up, 57 $(31.8 \%)$ out of 179 people had quit smoking. The patients who quit smoking classified as Group 1 and those who did not as Group 2. There was no difference between Group 1 and Group 2, in terms of gender, age, working status and education level ( $\mathrm{p}$ $=0.356, \mathrm{p}=0.421, \mathrm{p}=0.603, \mathrm{p}=0.465$, respectively). Marital status was a protective factor for smoking cessation ( $\mathrm{p}=0.049 \mathrm{OR}=0.5195 \% \mathrm{CI}$ $=0.267-0.961)$ (Table 1).

Very low-moderate addicts (FTND score $\geq 5$ ) and high-very high addicts (FTND score> 5) were compared in terms of smoking cessation status. There was no significant relationship between smoking cessation and FTND score $(\mathrm{p}=0.297)$. (Table 2).
Table 1. The effect of socio-demografic characteristics on smoking cessation

\begin{tabular}{|c|c|c|c|c|c|c|}
\hline & \multicolumn{2}{|c|}{ Group 1} & \multicolumn{2}{|c|}{ Group 2} & \multirow[t]{2}{*}{$\mathbf{p}$} \\
\hline & & $\mathbf{N}$ & $\%$ & $\mathbf{N}$ & $\%$ & \\
\hline \multirow{2}{*}{ Gender } & Male & 36 & 63.2 & 82 & 67.2 & \multirow{2}{*}{0.356} \\
\hline & Female & 21 & 36.8 & 40 & 32.8 & \\
\hline \multirow{2}{*}{$\begin{array}{l}\text { Age } \\
\text { (year) }\end{array}$} & $18-44$ & 39 & 68.4 & 80 & 65.6 & \multirow{2}{*}{0.421} \\
\hline & $\geq 45$ & 18 & 31.7 & 42 & 34.4 & \\
\hline \multirow{2}{*}{$\begin{array}{l}\text { Working } \\
\text { status }\end{array}$} & Employee & 50 & 87.7 & 107 & 87 & \multirow{2}{*}{0.603} \\
\hline & Unemployeed & 7 & 12.3 & 15 & 12.3 & \\
\hline \multirow{3}{*}{$\begin{array}{l}\text { Education } \\
\text { status }\end{array}$} & $\begin{array}{c}\text { Secondary } \\
\text { scholl and } \\
\text { under }\end{array}$ & 11 & 19.3 & 27 & 22.1 & \multirow{3}{*}{0.465} \\
\hline & High school & 12 & 21.1 & 34 & 27.9 & \\
\hline & University & 34 & 59.6 & 61 & 50 & \\
\hline \multirow{2}{*}{$\begin{array}{l}\text { Marital } \\
\text { status }\end{array}$} & Married & 29 & 50.9 & 42 & 34.4 & \multirow{2}{*}{0.049} \\
\hline & Single & 28 & 49.1 & 80 & 65.6 & \\
\hline
\end{tabular}

Group 1: patients who quit smoking

Group 2: patients who do not quit smoking

Table 2. The relationship between FTND smoking cessation status

\begin{tabular}{|c|c|c|c|c|c|}
\hline \multirow{2}{*}{ FTND } & \multicolumn{2}{|c|}{ Group 1} & \multicolumn{2}{|c|}{ Group 2} & \multirow{2}{*}{$\mathbf{P}$} \\
\hline & $\mathbf{N}$ & $\%$ & $\mathbf{N}$ & $\%$ & \\
\hline$\leq 5$ & 34 & 59.6 & 66 & 54.1 & \multirow{2}{*}{0.297} \\
\hline$>5$ & 23 & 40.4 & 56 & 45.9 & \\
\hline
\end{tabular}

FTND: Fagerström Test for Nicotine Dependence

Group 1: patients who quit smoking

Group 2: patients who do not quit smoking

In Group 1, 46 patients $(80.7 \%)$ did not have comorbidity, while in Group 2, 46 patients (37.7\%) had comorbidity. The presence of comorbidity in Group 1 was significantly lower than Group 2 ( $\mathrm{p}=$ 0.010) (Table 3).

Smoking cessation rates were evaluated according to the treatment method used. In Group 1, the ratios of different treatment methods that were used were as follows; nicotine replacement therapy (NRT) and behavioural therapy $14 \% \quad(n=8)$, varenicline and behavioural therapy $35.1 \%(\mathrm{n}=20)$, bupropion and behavioural therapy $21.1 \%(\mathrm{n}=12)$, combined treatment (varenicline, bupropion and behavioural therapy) $7 \% \quad(n=4)$. When the distribution of treatment methods was examined, behavioural treatment with varenicline was the most common method in both groups. No significant difference was observed between the two groups in 
terms of treatment methods used $(\mathrm{p}=0.541)$ (Table $4)$.

Table 3. The presence of another smoker at home, the presence of comorbidity, previous attempts to quit smoking and the assessment of smoking cessation

\begin{tabular}{|c|c|c|c|c|c|c|}
\hline & & \multicolumn{2}{|c|}{ Group 1} & \multicolumn{2}{|c|}{ Group 2} & \multirow[t]{2}{*}{$\mathbf{P}$} \\
\hline & & $\mathbf{N}$ & $\%$ & $\mathbf{N}$ & $\%$ & \\
\hline \multirow{2}{*}{$\begin{array}{l}\text { Another } \\
\text { smoker in } \\
\text { the home }\end{array}$} & Present & 34 & 59,6 & 67 & 54,9 & \multirow{2}{*}{0.333} \\
\hline & Absent & 23 & 40,4 & 55 & 45,1 & \\
\hline \multirow{2}{*}{ Comorbidity } & Present & 11 & 19,3 & 46 & 37,7 & \multirow{2}{*}{0.010} \\
\hline & Absent & 46 & 80,7 & 76 & 62,3 & \\
\hline \multirow{2}{*}{$\begin{array}{l}\text { Attempt to } \\
\text { quit }\end{array}$} & Yes & 35 & 59,6 & 66 & 54,1 & \multirow{2}{*}{0.279} \\
\hline & No & 23 & 40,4 & 56 & 45,9 & \\
\hline
\end{tabular}

Group 1: patients who quit smoking

Group 2: patients who do not quit smoking

Table 4. Evaluation of methods used for cessation treatment

\begin{tabular}{lccccc}
\hline & Group 1 & \multicolumn{2}{c}{ Group 2 } & P \\
\cline { 2 - 4 } & $\mathbf{N}$ & $\mathbf{\%}$ & $\mathbf{N}$ & $\mathbf{\%}$ & \\
\hline NRT+ BT & 8 & 14 & 23 & 18,9 & \\
\cline { 1 - 4 } Vareniclin + BT & 20 & 35,1 & 44 & 36,1 & \\
\cline { 1 - 4 } Bupropion + BT & 12 & 21,1 & 31 & 25,4 & 0.541 \\
\hline Behavioral therapy & 13 & 22,8 & 16 & 13,1 \\
\hline Combined treatment & 4 & 7 & 8 & 6,6 & \\
\hline
\end{tabular}

Group 1: patients who quit smoking

Group 2: patients who do not quit smoking

NRT: Nicotine replacement therapy

BT: Behavioral therapy

\section{Discussion}

The use of cigarettes and other tobacco products is an important public health problem and puts a huge burden on the national economy (WHO Report on the Global Tobacco Epidemic 2019). Today, smoking addiction, which is accepted as a disease, can be successfully treated with professional support (Karlıkaya et al., 2006). For this reason, WHO recommends that nicotine addicts should be encouraged to quit smoking and that the health system concentrates on smoking cessation methods and helps patients.

It has been reported that long-term success in self-quitters is less than 10\% (Rigotti, 2012).

Studies have shown that outpatient clinics for smoking cessation increase the success rate (Carlson et all., 2002; Godfresten, 2008; Bize et al., 2010) One-year smoking cessation rate in our outpatient clinic was $31.8 \%$. In similar studies conducted in our country, 1-year dropout rates were found to be 36.5\% and 40.4\% (Saglam, 2012; Argüder et al.,
2013). In a Canadian study, the 1 -year dropout rate was $43 \%$ (Carlson et al., 2002). The fact that the family of the individual was included in the social support program in this study, may be a factor that increases the success of quitting. In a Swiss study, the 1-year dropout rate was $27.1 \%$ (Bize et al., 2010).

In our study, the mean age at which the patients smoked for the first time was quite early $(17.79 \pm$ 4.52 years) and more than half of the patients $(50.8 \%)$ had started smoking before the age of 20 . Therefore an effective and correct approach towards smoking cessation in all age groups and especially in adolescents and early youth will be helpful to decrease the smoking rates and also quality of life and life expectancy could be increased. Beginning of smoking in adolescence period causes to become highly addictive and these individuals quit smoking more difficult. Tobacco Industry is therefore particularly target young people in their advertisements (Ozlu, 2002) Global Youth Tobacco Survey was assessed in 2017 at the age group of 1315 years' students in a nationwide report on Turkey. $17.9 \%$ of students ( $23.2 \%$ of boys, $12.1 \%$ of girls) currently smoked a tobacco product, $7.7 \%$ (9.9\% of boys and $5.3 \%$ of girls) were still smoking and $40.2 \%$ ( $46.8 \%$ of males and $33.1 \%$ of females) have tried a tobacco product at least once (Global Youth Tobacco Survey, Turkey, 2017).

In a study conducted by Şahbaz et al., it was shown that being married had a positive effect on smoking cessation success (Sahbaz et al., 2007). Similarly, in a study from England which had ten years' follow-up period, the rate of smoking cessation was significantly higher in the married individuals compared to those were unmarried (Chandola et al., 2004). In our study, in accordance with the literature, smoking cessation rate was higher in married patients. This may be due to the fact that married individuals are more determined to quit smoking because of their sense of responsibility and protection towards their families.

We found that absence of comorbidity had a positive effect on smoking cessation success. In the literature, there are studies reporting that patients with chronic disease quit smoking more difficult than those without. One study showed that patients with COPD quit smoking more difficult than healthy smokers (Solak et al., 2006; Onen et al., 2010). This made us think that patients with comorbidity may have been thought smoking cessation unnecessary because of their poor health. Contrary to these results, the presence of comorbidity has been 
reported to have a positive effect on smoking cessation success in two studies (Can et al., 2004; Global Initiative for Chronic Obstructive Lung Disease (GOLD) Guidelines, 2011).

In a meta-analysis, it was reported that all forms nicotine replacement therapies increased smoking abstinence by 1.58 times (95\% CI $=1.50-1.66$ ) (Parsons et al., 2009). In another meta-analysis, the quit rate for six months was $22 \%$ in the nicotine patch group and 22\% in the placebo group (Fiore et al., 1994). In our study, we did not only use NRT, but we found a one-year smoking cessation rate of $31.6 \%$ in individuals with NRT and behavioural therapy. The smoking cessation rate was $27 \%$ (Roddy, 2004) and 28\% in two studies using bupropion treatment for six months (Hays et al., 2001). In a study comparing bupropion and nicotine patches, after 9 weeks of treatment, cessation rates were $32.5 \%$ for placebo, $41.4 \%$ for nicotine patches, $57.8 \%$ for bupropion, and $66.1 \%$ for bupropion and NRT combination. At the end of 1 year, cessation rates were $35.5 \%$ in the combination group, $30.3 \%$ in the bupropion group, $16.4 \%$ in the patch group, and $15.6 \%$ in the placebo group (Jorenby et al., 1999). In these studies, it was not indicated whether behavioural therapy was added or not to medical treatment (Jorenby et al., 1999; Hays et al., 2001; Roddy, 2004). In our study, quitting rates were $29.4 \%$ in the bupropion and behavioural treatment group, compared to quitting rate with bupropion in the literature and $31.6 \%$ in the NRT and behavioural treatment group. In a study comparing varenicline and NRT, one group received $1 \mathrm{mg}$ varenicline twice a day and the other group received $21 \mathrm{mg}$ transdermal patch. At the end of the twelve weeks of standard treatment regimen, quitting rates with varenicline were significantly higher than rates with standard transdermal nicotine treatment $(56 \%$ and $43 \%$, respectively) (Cahill et al., 2009). In our study, the difference between varenicline and NRT in terms of smoking cessation was not significant.

In a meta-analysis, it was shown that smoking cessation rate increased significantly for six months in parallel with the total minute duration in behaviour therapy contacts. The ratios of quitting were $14 \%$ in one to three minutes of counselling, $19 \%$ in 4-30 minutes of counselling and $27 \%$ in 3190 minutes of counselling and $11 \%$ dropout rates was found among patients who did not take counselling therapy was given (Fiore, 2011). In our study, the rate of one-year smoking cessation was $31.7 \%$ in individuals who received only behavioural treatment.
In a placebo-controlled study which enrolled 51 patients the authors evaluated the use of combinations of bupropion SR and nicotine patch, and nicotine gum and behavioural therapy; they showed that addition of bupropion SR to the treatment regimen increased the reduction rate more than 50\% (Evins et al., 2007). In our study, the rate of one-year smoking cessation was $41.7 \%$ in individuals using combined therapy. However, in our study, since the number of individuals who received combined treatment was very small, individuals were examined as one group heading, regardless of their drug differences.

Our study had some limitations. Retrospective method of the study may have been prevented the standardization of treatment. Because it is a singlecenter study, the patient population does not represent the whole population. In our study behavioural therapy applied to the patients was not uniform. So this could cause a confounding effect on the results. We had to exclude patients who had missing follow-up and quit smoking data. This limited the number of included patients.

As a result; Although there was no significant difference among the quitting methods used in our study, the quit rates $(31.8 \%)$ were higher than the non-intervention quit rates reported in the literature. Patients with a high level of addiction benefit from smoking cessation methods. Being married in the smoking cessation process may positively affects the success of cessation. Since smoking is started mostly in adolescents and early youth, there is an urgent need for preventive measures to stop smoking and especially not to start.

Ethics Committee Approval: Ethics committee approval was received for this study from the ethics committee of Ufuk University Faculty of Medicine, Non-Interventional Clinical Research Evaluation Commission. 06.06.2013-060620137

Peer-review: Externally peer-reviewed. Author Contributions: Concept-E.A.; Design E.S.G.; Supervision- E.A; Funding-None Materials-E.S.G.; Data Collection/Data Process- E.S.G.; Analyse or Comment- E.S.G.; Literature Scanning- E.S.G.; Writer of Paper- E.S.G.; Critical Review- E.A.

Conflict of Interest: No conflict of interest was declared by the author. Financial Disclosure: The author declared that this study hasn't received no financial support. 


\section{References}

Arguder E, Karezli A, Hezer H, Kılıc H, Er M, Hasanoglu HC, et al. Factors Affecting the Success of Smoking Cessation. Turk Thorac J 2013; 14:81-87

Bize R, Willi C, Chiolero A, Stoianov R. Participation in a population-based physical activity programme as an aid for smoking cessation: randomized trial. Tobacco Control 2010; 19:488-494

Cahill K, Stead LF, Lancaster T. Nicotine receptor partial agonists for smoking cessation. Cochrane Database Syst Rev. 2010; 8;(12):CD006103.

Can G, Oztuna F, Ozlu T. The Evaluation of Outpatient Smoking Cessation Clinic Results Tuberculosis and Thorax 2004;52: 69-74,

Carlson LE, Goodey E, Bennet MH, Taenzer B. The addition of social support to a community-based large-group behavioral smoking cessation intervention: Improved cessation rates and gender differences. Addictive Behaviors 2002;27:547-559

Chandola T, Head J, Bartley M. Socio-demographic predictors of quitting smoking: how important are household factors? Addiction. 2004;99(6):770-777

Demir T. Common psychiatric disorders in Turkey. Symposium series 2008; 62:231-238

Evins AE, Carter C, Culhane MA, Birnbaum A, Horowitz J, Hsieh H, et al. A 12-week doubleblind, placebo-controlled study of Bupropion SR added to high dose dual nicotine replacement therapy for smoking cessation or reduction in schizophrenia, J Clin Pyscopharmacol. 200727 (4):380-386

Fiore MC, Baker TB. Treating Smokers in the Health Care Setting, N Engl J Med 2011;365:1222-1231

Fiore MC, Smith SS, Jorenby DE, Baker TB. The effectiveness of the nicotine patch for smoking cessation. A meta-analysis. JAMA 271: 1940-7, 1994

Freid VM, Prager K, Mackay AP, Xia H. Chartbook on Trends in the Health of Americans. National Center for Health Statistics, Hyattsville, Maryland: 2003

Global Adult Tobacco Survey, Turkey, 2016 . (cited 2019 August 5) Available from:

https://nccd.cdc.gov/GTSSDataSurveyResource s/Ancillary/DownloadAttachment.aspx ?ID=345 2
Global Initiative for Chronic Obstructive Lung Disease (GOLD) Guidelines 2011 www.goldcopd.org

Global Youth Tobacco Survey, Turkey, 2017. (cited 2019 August 5) Available from:

https://extranet.who.int/ncdsmicrodata/index.ph $\mathrm{p} / \mathrm{catalog} / 477$

Godfresten NS, Lam TH, Hansel TT, Leon ME, Gray N, Dresler C et al. COPD-related morbidity and mortality after smoking cessation: status of evidence. Eur Respir J 2008, 32:844-53.

Hays JT, Hurt RD, Rigotti NA, Niaura R, Gonzales D, Durcan MJ, Sachs DP, Wolter TD, Buist AS, Jonhston JA, White JD, Sustained release Bupropion for pharmacologic relapse prevention after smoking cessation, a randomized, controlled trial, Ann. Intern. Med 2001; 18,135(6):423-433

Heatherton TF, Kozlowski LT, Frecker RC, Fagerström KO. The Fagerström Test for Nicotine Dependence: a revision of the Fagerström Tolerance Questionnaire. Br J Addict 1991;86: 1119-1127

Jorenby DE, Leishchow SJ, Nides MA, Rennard SI, Jonhston JA, Hughes AR, et al. A controlled trial of sustained-release bupropion, a nicotine patch, or both for smoking cessation. N Eng J Med 1999; 340:685-691

Karlıkaya C, Oztuna F, Solak Z, Ozkan M. Tobacco Control, Turk Thorac J 2006;7(1):51-64

Karnath B. Smoking cessation. Am J Med 2002;112:399-405

Mackay J, Eriksen M. The Tobacco Atlas. World Health Organization. Part one 6. Cigarette consumption 2002

Onen ZP, Sen E, Eriş Gülbay B, Oztürk A, Akkoca Yildiz $O$, Acican $T$ et al. Comparing the effectiveness of different treatment modalities on the smoking cessation rates. Tuberculosis and Thorax, 2010; 58:385-92

Ozlü T, Youth and Smoking, Ozyardimci N. editor, Smoking and Health, Bursa 2002; p.74-84

Parrott S, Godfrey C, Raw M, et al. Guidance for commissioners on the cost effectiveness of smoking cessation interventions. Turkish Thoracic Journal, 1998; 53: 1-38.

Parsons AC, Shraim M, Inglis J, Aveyard P, Hajek $\mathrm{P}$, Interventions for preventing weight gain after smoking cessation. Cochrane Database Syst Rev. 2012 Jan 18;1:CD006219.

Rigotti NA, treatment of tobacco uses and dependence. N Eng J Med 2002:346:505-512 
Roddy E. Bupropion and other nonnicotine pharmacotherapies, BMJ 2004 328:509511

Saglam L. Investigation of the results of a smoking cessation clinic and the factors associated with success. Turk J Med Sci 2012;42:515-522.

Solak ZA, Başoğlu ÖK, Erdinç E, Success of smoking cessation in patients with chronic obstructive pulmonary disease. Tuberculosis and Thorax, 2006;54:43-50

Sahbaz S, K1lınc O, Gunay T, Ceylan E, The Effects of Smoking Properties and Demographic Properties on the Results of Smoking Cessation Therapy. Turk Thorac J, 2007;8(2):110-114

Uysal MA, Kadakal F, Karşidağ C, Bayram NG, Uysal O, Yilmaz V. Fagerström test for nicotine dependence: Reliability in a Turkish sample and factor analysis. Tuberculosis and Thorax 2004;52:115-121.

WHO Report on the Global Tobacco Epidemic 2019- MPOWER. (cited 2019 August 5) Available from: http://www.who.int/tobacco/ mpower/gtcr_download/en/index.html 